\title{
Dense-core granules in neuroendocrine cells and neurons release their secretory constituents by piecemeal degranulation (Review)
}

\author{
ENRICO CRIVELLATO ${ }^{1}$, BEATRICE NICO ${ }^{2}$, EUGENIO BERTELLI ${ }^{3}$, \\ GASTONE G. NUSSDORFER ${ }^{4}$ and DOMENICO RIBATTI ${ }^{2}$
}

\author{
${ }^{1}$ Department of Medical and Morphological Research (Section of Anatomy), School of Medicine, \\ University of Udine, I-33100 Udine; ${ }^{2}$ Department of Human Anatomy and Histology, School of Medicine, \\ University of Bari, I-70124 Bari; ${ }^{3}$ Department of Pharmacology Giorgio Segre (Section of Morphology), \\ School of Medicine, University of Siena, I-53100 Siena; ${ }^{4}$ Department of Human Anatomy and Physiology \\ (Section of Anatomy), School of Medicine, University of Padua, I-35121 Padua, Italy
}

Received June 2, 2006; Accepted July 26, 2006

\begin{abstract}
The term piecemeal degranulation (PMD) refers to a slow releasing process mediated by vesicular transport of stored secretory granule contents. This form of cell secretion was first proposed for basophils, mast cells and eosinophils, but evidence has begun to accumulate that PMD also occurs in dense-core granules of neuroendocrine cells and neurons. This review summarizes the electron-microscopic evidence that has been gathered in support of this view and also discusses the possible physiological significance of PMD in this class of secretory organelles in comparison with 'full fusion' and 'kiss-and-run' exocytosis.
\end{abstract}

\section{Contents}

1. Introduction

2. Piecemeal degranulation is mediated by vesicular transport

3. Dense-core granules of neuroendocrine cells and their content release

4. Piecemeal degranulation in enteroendocrine cells

5. Piecemeal degranulation in adrenal chromaffin cells

6. Piecemeal degranulation in pancreatic A and B cells

7. Piecemeal degranulation in thymic neuroendocrine cells

8. Piecemeal degranulation in neurons

9. Functional significance of piecemeal degranulation in neuroendocrine cells and neurons

10. Concluding remarks

Correspondence to: Dr E. Crivellato, Department of Medical and Morphological Research (Section of Anatomy), University of Udine Medical School, P.le Kolbe, n. 3, I-33100 Udine, Italy

E-mail: enrico.crivellato@uniud.it

Key words: piecemeal degranulation, dense-core granules, neuroendocrine cells, neurons, 'full fusion' exocytosis, 'kiss-andrun' exocytosis

\section{Introduction}

In the early 1970s, Ann Dvorak and co-workers identified a novel type of cell secretion that they termed piecemeal degranulation (PMD). This form of granule discharge was recognized in guinea pig and human basophils participating in skin contact allergic reactions or infiltrating tumors (referenced fully in refs. 1,2). When examined by transmission electron microscopy, these cells exhibited partially or completely emptied granules in the absence of granuleto-granule or granule-to-plasma membrane fusions. It soon appeared that PMD was substantially different from exocytosis, which affected the extrusion of stored material through granule fusion to the cell plasma membrane. The term PMD was coined because basophil granules showed focal pieces or packets of lost particles leaving characteristic patchy areas of electrondensity beside luciency zones. In addition to granule changes, the cytoplasm of basophils presented a large number of smooth, $30-150 \mathrm{~nm}$ in diameter, membrane-bound vesicles. Some of these vesicles were filled with particles similar in structure and electron-density to those contained in the granules, while others were apparently empty and appeared electron-lucent. Remarkably, vesicles were often seen attached to granules, in a process of budding from or fusing with the perigranule membrane. The PMD phenotype was later recognized in mast cells localized at sites of chronic inflammatory response, and a careful survey in different human pathologies led to the conclusion that PMD, not anaphylactic degranulation, was the most common release reaction in these cells (reviewed in ref. 3). Next, PMD was identified in eosinophils and granule changes reflecting PMD were detected in human and guinea pig models of asthma and respiratory allergic reactions (4-6).

\section{Piecemeal degranulation is mediated by vesicular transport}

Dvorak and co-workers provided a theoretical model to explain how granules empty during PMD releasing reactions and gave rigorous kinetic bases to the movement of granule content within individual cells. The 'shuttling vesicle' hypothesis 


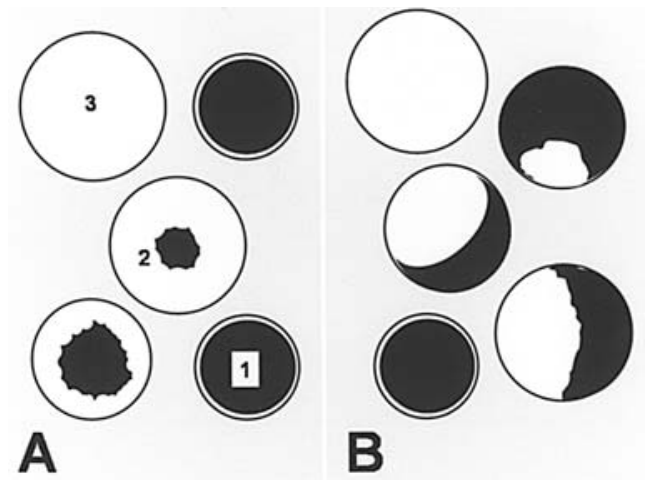

Figure 1. Schematic drawing illustrating the unique admixture of normal granules (1), activated granules with partially mobilized cargo (2) and empty containers (3) observable during PMD. Activated granules present either a 'haloed' (A) or 'semilunar' (B) pattern. Each granule maintains its structural integrity and does not fuse with other granules or the plasma membrane.

formulated by Dvorak and Dvorak (7) postulated a vesicular transport mechanism to effect transfer of granule constituents outside the cells. This hypothesis received substantial experimental confirmation by a series of elegant electron microscopic investigations using ultrastructural tracers and purified cells stimulated in vitro by different secretagogues. According to this model, an outward flow of cytoplasmic vesicles loaded with granule materials effects granule emptying during PMD. Vesicles containing bits of granule contents bud from the perigranule membrane, move through the cytoplasm and fuse with the plasma membrane, leading to content discharge. Endocytic vesicles are retrieved from the plasma membrane, traverse the cytoplasm and fuse with granules in a closely coupled inward flow. If the rate and amount of vesicular traffic are balanced, granule containers empty in a piecemeal fashion, but maintain a constant size. If, on the other hand, the inward flow of the endocytic vesicles exceeds the outward flow of the exocytic vesicles, the granule chambers become enlarged. The latter event is what generally occurs during PMD.

The electron microscopic changes occurring during PMD can be summarized in a series of specific diagnostic criteria (8): i) PMD, a discrete process affecting single granules in an asynchronic stepwise progression, generally results in a unique granule polymorphism, consisting in an admixture of normal resting granules, activated granules with enlarged chambers and diminished constituents, and empty dilated containers (Fig. 1); ii) remarkably, each granule does not fuse with the others or with the cell membrane, but maintains its close individual structure during the entire releasing process; iii) the residual secretory material contained in activated granules presents piecemeal loss of constituents leading to 'semilunar' or 'haloed' patterns (Figs. 1 and 2); iv) a proportion of granules exhibits surface budding projections, which are either apparently empty (electron-lucent) or filled by the same electron-dense material that constitutes the granule; and v) small, smooth, membrane-bound electron-dense or electronlucent vesicles are recognizable attached to the granules or free in the intergranular cytosol or close to the plasma membrane. Thus, identification of PMD relies upon specific ultrastructural criteria, which refer to both granule and cytoplasmic changes.

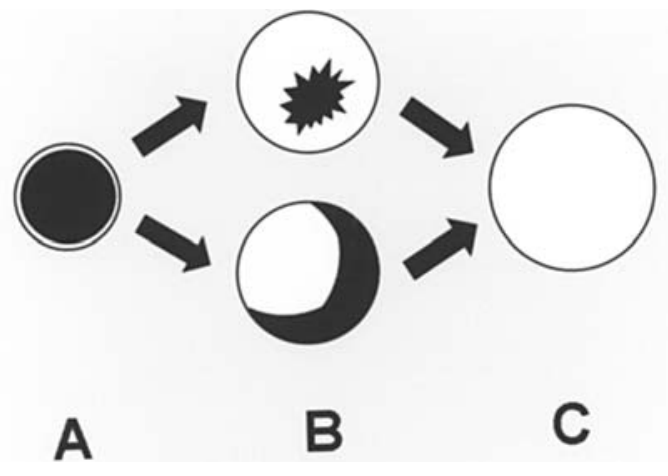

Figure 2. Schematic drawing illustrating the structural changes observed in a dense-core granule during PMD. (A) Normal, resting granule presents electron-dense content and closely adhering limiting membrane. (B) Upon activation, it undergoes a process of vesicle-mediated mobilization of secretory constituents. Granule remnant appears either as a fringed core surrounded by lucent rim ('haloed' pattern) or as an electron-dense accumulation adherent to the perigranular membrane ('semilunar' pattern). Release of cargo material is coupled with enlargement of the granule chamber. (C) This process eventually leads to formation of a dilated, empty container.

\section{Dense-core granules of neuroendocrine cells and their content release}

More than 30 years have elapsed since the first PMD report and the interest in this subject has recently gained new impulse. It appears that distinct types of neuroendocrine cells express ultrastructural features strongly indicative of PMD. The neuroendocrine system comprises a vast population of secretory cells, which are either aggregated into purely secretory tissues, such as gland structures, or dispersed within the epithelia and connective components of various organs. Cells of the neuroendocrine system have been previously referred to with different names, such as argentaffin or argyrophil cells, small intensely fluorescent cells, APUD (amine precursors uptake and decarboxylation) cells, peptide-producing cells, enterochromaffin cells (in the stomach, intestine and bile ducts), and Kulchitsky cells (in the lung). Typical neuroendocrine cells are the chromaffin cells of the adrenal medulla, whose name refers to the property of their cytoplasm to give an intense yellow-brown staining when treated with chromium salts. Both the alimentary and the respiratory tracts contain dispersed or aggregated neuroendocrine cells; the pancreatic islets of Langerhans are a remarkable example of such cell types. All neuroendocrine cells share common ultrastructural features and their hallmark is the dense-core secretory granule, which by conventional electron microscopy appears as a membranebound electron-dense structure, whose size and shape vary among the different neuroendocrine cell types according to the kind of contained molecules. These organelles store hormone peptides in a specific structural complex with biogenic amines, ATP, and a series of matrix proteins like chromogranins and secretogranins; in addition, they contain peptide processing enzymes (endoproteases and carboxypeptidases), glycoproteins, ascorbic acid and $\mathrm{Ca}^{2+}(9)$. Of interest, the limiting membranes of neuroendocrine granules express specific proteins, such as the vesicle receptor (vSNARE) VAMP2 (vesicle-associated membrane protein-2 or synaptobrevin-2) $(10,11)$, which is necessary for membrane fusion; phogrin, which aggregates 
with specific cargo proteins (12), and the $\mathrm{Ca}^{2+}$ sensor synaptotagmin I and II $(13,14)$. Secretory granules in neuroendocrine cells are sorted in the trans-Golgi compartment and undergo a process of maturation in the cell cytoplasm before acquiring secretory competence (15). These organelles share many common properties with large dense-core vesicles in neurons. Accordingly, a unifying concept including both neuroendocrine granules and large dense-core vesicles has been developed (16). These structures are now comprehensively referred to as dense-core granules (DCG), irrespective of whether they are located in neuroendocrine cells or neurons $(15,17-20)$.

It is widely accepted that DCG release their secretory constituents by exocytosis (11). This model applies to both neurotransmission and hormone release from a variety of neuroendocrine cells and outlines a common molecular mechanism for membrane fusion involving a large number of proteins, including the SNARE (soluble N-ethylmaleimidesensitive factor attachment protein receptor) family of proteins or SNARE complex, which is believed to drive membrane fusion $(16,21)$. According to this model, granules actively move to and dock at specific sites of the cell plasma membrane, the so called 'active zone'. Here, after stimulation by specific secretagogues, they undergo complete fusion to the plasma membrane with resulting formation of ' $\Omega$-shaped structures visible by transmission electron-microscopy. In this way, the secretory constituents packed in the granules dissolve and are entirely discharged from the cell, while the perigranular membrane collapses to and is integrated in the plasma membrane ('full fusion' exocytosis). Components of the granule membrane are subsequently recaptured by clathrinmediated endocytosis at sites distant from active zones and then transported to the endosomal compartment for refilling and resorting. Recently, an alternative (or complementary) mode of exocytosis has been proposed as a means of DCG release. This process has been variably referred to as 'kissand-run' exocytosis, 'fuse-pinch-and-linger', 'cavicapture' or 'porocytosis' (22-26). Accordingly, the granule limiting membrane contacts the plasma membrane and a transient and reversible fusion pore is established. This momentary communication between the granule lumen and the extracellular environment allows escape of variable amounts of granule cargo. The perigranular membrane, however, does not merge with the plasma membrane, but is immediately retrieved back into the cell after fusion pore resealing (27-29). As a consequence, the DCG partially releases its secretory constituents on a millisecond time scale, but maintains the structural integrity and can be reused without necessity of complete rebuilding. 'Kiss-and-run' exocytosis has been established through biophysical approaches, such as patchclamp capacitance measurement of the cell surface area and amperometric measurement of the release of single granule contents (11). This hypothesis has received convincing support by 'evanescent field' microscopy (also known as total internal reflection microscopy), a real-time imaging technique that allows DCG to be tracked before and after fusion to the plasma membrane (30-32). It has also been recognized that the cell can switch between 'full fusion' and 'kiss-and-run' events and that this process is regulated by $\mathrm{Ca}^{2+}$ concentration (33).

\section{Piecemeal degranulation in enteroendocrine cells}

Enteroendocrine cells are a class of entodermal-derived cells belonging to the diffuse neuroendocrine system. They are located to the superficial and gland epithelia lining the alimentary tract (34). These cells store in their DCG both biogenic amines, such as histamine and serotonin, and different peptides (35). At least 14 distinct types of enteroendocrine cells have been identified that produce characteristic profiles of hormone peptide secretion (36). Each cell type presents a distinctive pattern of regional distribution along the gastrointestinal tract and is morphologically distinguishable on the basis of the number, size, shape and electron-density of its DCG. Enteroendocrine cells participate in the regulation of the processes related to digestion and resorption of food. These functions are accomplished through paracrine and endocrine modes of action. In particular, 'short-loop' endocrine mechanisms, which imply messenger secretion within local gastrointestinal blood circuits, have been proved to regulate important alimentary functions, such as secretion of glands extrinsic or intrinsic to the gastrointestinal wall, peristalsis and blood supply $(35,37)$. Admittedly, these cells release their secretory contents by exocytosis.

However, different subtypes of enteroendocrine cells in the human and mouse gastrointestinal tracts have been shown to express a repertoire of granule changes that mirrored the PMD phenotype (38). Changes to granules consisted of organelle enlargement accompanied by focal loss of content material (Fig. 3A). Residual secretory constituents appeared either as fringed cores surrounded by lucent rims ('haloed' pattern) or as electron-dense piecemealed accumulations adherent to part of the perigranular membrane ('semilunar' pattern). Often, granule components were completely lost during the secretory process leaving empty, dilated containers. Remarkably, altered granules and empty containers were always intermingled with normal granules and fusion events among granules and between granules and the plasma membrane were never recognized. In addition, altered granules frequently displayed irregular profiles with stretched outlines, inward or outward indentations, or tail-like budding projections. Besides granule modifications, small, 30-150 nm diameter, membrane-bound electron-dense or electron-lucent vesicles were recognized to be free in the cytoplasm or closely associated with DCG. It was also found that their density was higher in those areas in which altered granules were more frequently observed.

\section{Piecemeal degranulation in adrenal chromaffin cells}

Chromaffin cells of the adrenal medulla are neuroendocrine cells which, like sympathetic neurons, derive from sympathoadrenal precursors in the neural crest, a transient structure formed early in embryonic development along the dorsal surface of the neural tube (39). Chromaffin cells are actually modified postganglionic sympathetic neurons of the autonomic nervous system that have lost axons, dendrites and other neuron-specific traits. These cells secrete both the classical neurotransmitters adrenaline and noradrenaline, and a number of other substances, such as chromogranins and neuroactive peptides, in response to various kinds of stimuli including the stressful ones (40-42). Neuropeptides co-stored with catechol- 


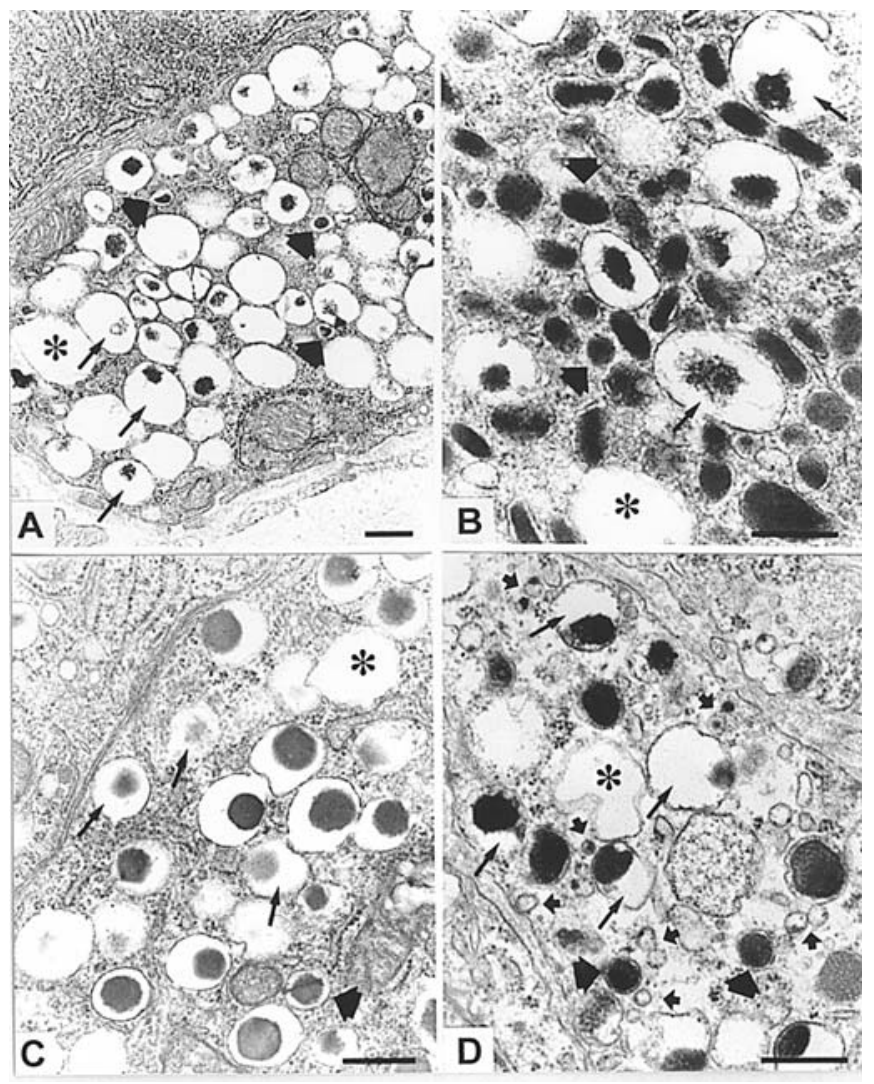

Figure 3. Transmission electron microscopy. Ultrastructural features indicative of PMD in different types of neuroendocrine cells. (A) Enteroendocrine cell of murine gastric body; (B) chromaffin cell of the mouse adrenal medulla; (C) B cell of pancreatic islet of Langerhans in the rat; and (D) neuroendocrine cell of the chick embryo thymus. All illustrated cells show admixtures of resting granules (thick arrows), enlarged granules with reduced contents (thin arrows) and large empty containers (asterisks), in the absence of granuleto-granule or granule-to-plasma membrane fusion. In D, numerous small, dense or lucent vesicles (small arrows) are observable attached to granules, free in the cytosol or close to the cell membrane. Scale bars, $0.5 \mu \mathrm{m}$.

amines in DCG are among other opioid peptides, neuropeptide$\mathrm{Y}$, substance-P, VIP and PACAP, beacon, neuropeptides B and $\mathrm{W}$, adrenomedullin and natriuretic peptides, which all are able to modulate adrenal cortex function (referenced in refs. 43-50). Released substances can act locally in a paracrine manner (43) or enter the bloodstream to act on distant targets in an endocrine fashion.

The current view is that adrenal chromaffin cells release their granule constituents by exocytosis, in the form of either 'full fusion' or 'kiss-and-run' exocytosis $(18,39,51,52)$. In recent years, however, compelling ultrastructural evidence of PMD pathway was found in chromaffin cells of the adrenal medulla. In the mouse and rat, where distinct populations of adrenaline- and noradrenaline-producing cells are recognizable, the expression of PMD was identified in both types of cells $(53,54)$. Normal resting chromaffin granules with an inner electron-opaque component and closely adhering limiting membrane were found admixed to enlarged granules with partially mobilized components and dilated empty containers (Fig. 3B). As in enteroendocrine cells, activated DCG exhibited either inner eroded cores surrounded by clear swollen haloes ('haloed' pattern) or peripheral densities close to the perigranule membrane and assuming a lunar shape ('semilunar' pattern).

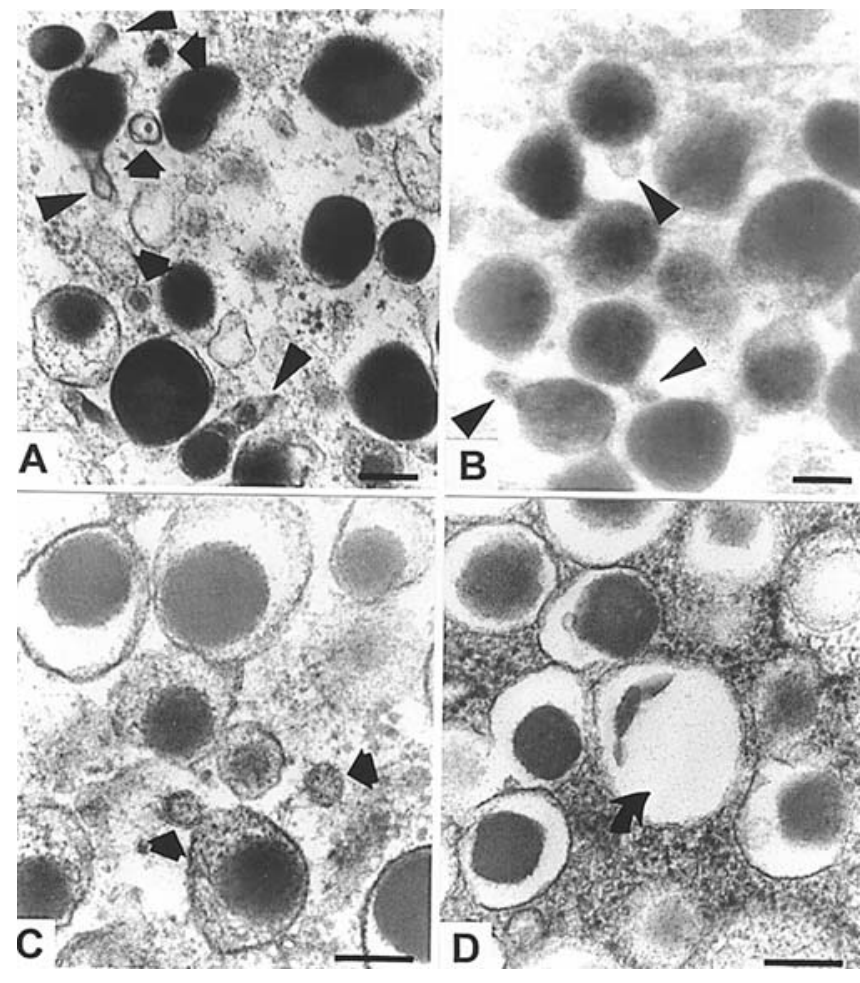

Figure 4. Transmission electron microscopy of dense-core granules in rat chromaffin cells (A and B), rat pancreatic A cells (C), and mouse pancreatic B cells (D). (A) Granules in chromaffin cells exhibit surface buds filled by electron-dense material (arrowheads); small vesicles loaded with dense cargo are recognizable in close proximity (arrows). (B) Both granule content and surface outpouches (arrowheads) react with zinc iodide-osmium tetroxide (ZIO). (C) Small, loaded vesicles (arrows) are identifiable near dense-granules in an A cell. (D) B-cell granule (curved arrow) shows 'semilunar' pattern. Scale bars, $0.2 \mu \mathrm{m}$.

Notably, altered granules and empty containers preserved their structural integrity, as no fusion events with the plasma membrane or with neighbouring granules were observable. Short blebs or more elongated buds filled by chromaffin material were seen on the surface of many granules (Fig. 4A). In addition, a cohort of variably sized (30-150 nm diameter) and electron-dense vesicles was found either close to the granules or in the intergranular cytosol (Fig. 4A).

Similar features were observed in human chromaffin cells excised from adrenal pheochromocytomas (55). In both tumor pheochromocytes and normal chromaffin cells situated around the tumor mass, ultrastructural features were comparable with those recognized in mouse and rat chromaffin cells. Of interest, quantitative morphometric analysis demonstrated that the frequency of ultrastructural features indicative of PMD, such as percentage of altered granules and density of cytoplasmic vesicles, were significantly increased in tumor chromaffin cells in comparison with non-tumor cells. Collectively, these data suggest that PMD is a common mechanism responsible for cell degranulation in adrenal chromaffin cells and that the PMD reaction is settled at a higher level in adrenal tumor cells.

Recently, a histochemical procedure based on zinc iodideosmium tetroxide complexes has been used to fix rat chromaffin cells (56). This method is known to highlight catecholic compounds both at the light and electron microscopic level. 
Ultrastructural analysis of chromaffin cells treated in such a way revealed fine heavily electron-dense precipitates in DCG. The same reactivity was observed in the emerging buds on the surface of chromaffin granules as well as in many cytoplasmic vesicles, indicating that all these structures contain the same reactive material (Fig. 4B). These observations add further support to the hypothesis that secretion from DCG in chromaffin cells may be effected by a vesicle-mediated transport mechanism implicating transfer of loaded vesicles from the granule surface to the cell membrane.

\section{Piecemeal degranulation in pancreatic $A$ and $B$ cells}

The pancreatic islet of Langerhans comprises entodermalderived cells that synthesize and secrete distinct peptide hormones (57). Four major cell types are recognized in many mammalian species: A cells, which contain glucagon; B cells, which contain insulin; D cells, which contain somatostatin; and PP cells, which contain pancreatic polypeptide $(58,59)$. For the most part, studies have been accomplished on secretion of B cells. Insulin is stored in DCG of pancreatic B cells and released upon food (glucose) ingestion. Insulin secretion occurs by exocytosis in the form of either 'full-fusion' or 'kiss-andrun' exocytosis (60). Electron microscopy has provided support for both types of secretory models. Opening of single B-cell granules to the plasma membrane has been visualized along with sequential fusion of granules leading to formation of secretory chains (sequential and compound exocytosis) (61). In addition, exocytosing secretory granules do not appear to always completely collapse with the plasma membrane but rather form small fusion pores, supporting the possibility that some of these fusion pore openings might be transient and would retract and close (62). Glucagon is also released by pancreatic A cells through exocytic mechanisms upon stimulation by various secretagogues (63). As a matter of fact, both $\mathrm{A}$ and $\mathrm{B}$ cells are well endowed with exocytic molecular machinery (64).

Recently, the fine structure of pancreatic A and B cells has been investigated in the mouse and rat, and preliminary results indicate that these cells express a repertoire of electronmicroscopic features that are highly reminiscent of the PMD phenotype (Crivellato and Bertelli, unpublished data). B cells, in particular, often contain a highly polymorphic population of non-fused granules essentially made up of three distinct structural classes: i) granules with moderately electron-dense texture and closely adhering limiting membrane; ii) enlarged granules with strongly electron-dense or incompletely dissolved remnants surrounded by clear haloes; and iii) empty vacuole containers (Fig. 3C). Even assuming that the characteristic ultrastructure of B-cell granules, with their dense core surrounded by a clear halo, may be partly the result of fixation or post-fixation artifacts, it is noteworthy that distinct B-cell granules present a unique 'semilunar' arrangement of residual constituents suggesting a piecemeal process (Fig. 4D). Other B-cell granules show amorphous remnants inside enlarged chambers indicating mobilization of granule components paralleled by remodeling of the limiting membrane. As biological membranes have very limited stretching compliance (65), it is reasonable to regard granule enlargement as an active process resulting from insertion of new membrane material into the limiting membrane. Clear or dense vesicles are actually recognizable in the proximity of B-cell granules, although with a lower frequency than in other neuroendocrine cells. Also A cells exhibit changes suggestive of the PMD pattern of secretion. They display a cytoplasmic admixture of resting moderately electron-dense granules; activated granules with enlarged size and reduced 'haloed' content material; and empty containers. In addition, some granules exhibit outpouches or budding projections of their limiting membrane and small dense or clear vesicles can be observed close to granules or in the perigranular cytoplasm (Fig. 4C).

\section{Piecemeal degranulation in thymic neuroendocrine cells}

The mammalian and avian thymus contains a heterogeneous population of neuroendocrine cells, which possess the characteristic appearance of amine- and peptide-storing cells (66). Their origin, biological significance and precise granule content are poorly understood but, in the chicken, thymus neuroendocrine cells have been recognized to store and release serotonin (67). In addition, ultrastructural evidence of exocytic images indicates that these cells are actively secreting (68). Neuroendocrine cells of the chicken thymus have been studied during embryonic life and they were found to include different cytological subsets, which are chiefly located to the developing medulla (69).

These cells contain variable amounts of DCG differing in shape, size and electron-density. They appear to express the distinctive ultrastructural pattern of PMD secreting cells. In fact, an admixture of normal unaltered granules, dilated granules with partially mobilized contents, and large empty containers was observable at low magnification (Fig. 3D). Dilated granules presented patchy losses of cargo material consistent with either 'haloed' or 'semilunar' patterns. At a higher magnification altered granules presented bud-like or tail-like protrusions, often filled with the same particles constituting the granule cargo, and an impressive number of smooth membrane-bound granulated or clear vesicles was observed in the intergranular cytoplasm or attached to granules (Fig. 3D).

\section{Piecemeal degranulation in neurons}

Neurons are highly differentiated secretory cells. They contain two types of secretory organelles, small synaptic vesicles and dense-core granules. These two organelles present different morphology and secretory content. Viewed by electron microscopy, small synaptic vesicles appear as clear vesicles with a regular diameter of $30-40 \mathrm{~nm}$; they store fast-acting neurotransmitters such as glutamate, $\gamma$-amino-butyric acid and acetylcholine. DCG, on the other hand, represent a heterogeneous group of variably sized vesicles (80 to $200 \mathrm{~nm}$ in diameter), showing an inner electron-dense content and storing slow-acting neurotransmitter peptides, alone or in association with amine-transmitters (70-72). Unlike small synaptic vesicles, which can undergo many cycles of emptying/ refilling at the site of synaptic bouton, DCG require loading with peptides and other constituents in the cell soma before moving to sites of release (15). This implicates the biology of DCG to be very different from that of small synaptic vesicles 


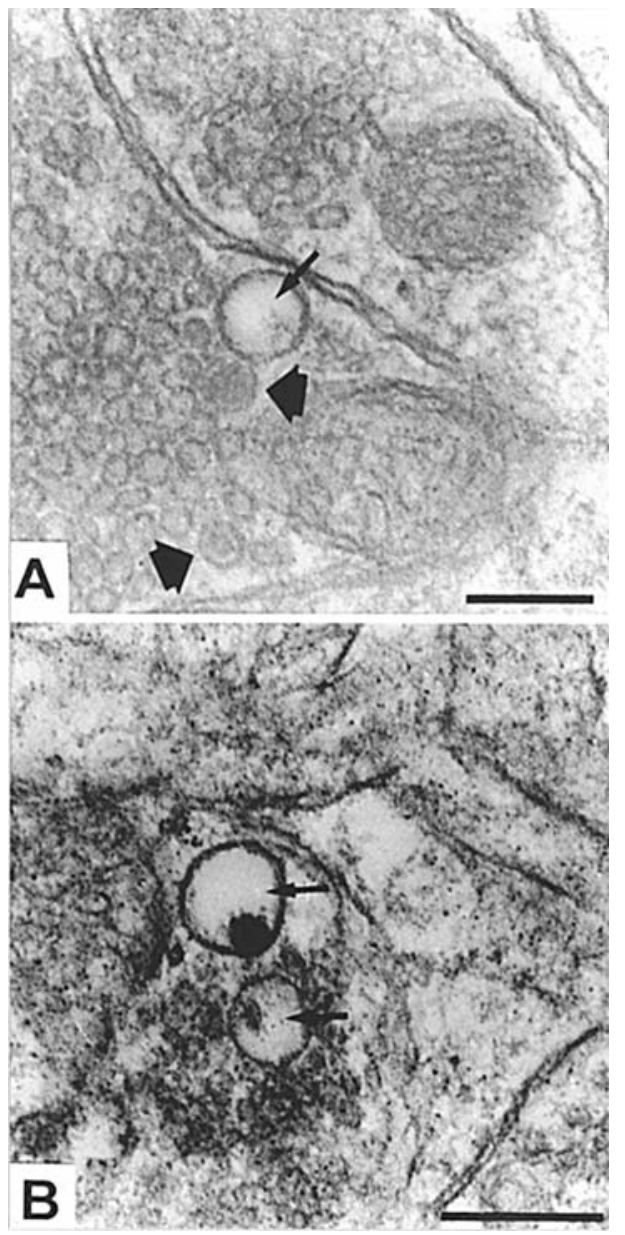

Figure 5. Transmission electron microscopy of dense-core granules in mouse neurons. (A) An almost empty container (thin arrow) is observable near two dense-granules characterized by normal shape and dimension (thick arrows), and numerous small synaptic vesicles. (B) Two dense-core granules (arrows) display enlargement of vesicle chamber paralleled by reduction of cargo constituents. Scale bars, $0.2 \mu \mathrm{m}$.

although the molecular machinery required for content release from either class of vesicles shows great similarity $(73,74)$. A single neuron can contain six or more different peptides stored within DCG. These peptides can be released not only by nerve terminals within synaptic cleft domains, but also from a variety of locations including dendrites, cell bodies and extrasynaptic axonal zones $(75,76)$. It is well documented that neurons extrude their messenger content from DCG by either 'full fusion' or 'kiss-and-run' exocytosis (77).

As DCG in neurons share chemical and ultrastructural properties with secretory granules in neuroendocrine cells (9), it has been explored whether DCG in neurons express PMD as well. As a matter of fact, ultrastructural morphologies indicative of a PMD releasing model have been recognized in the DCG of the mouse brain (78). Indeed, some DCG were shown to undergo enlargement of the vesicle chamber paralleled by reduction of cargo constituents (Fig. 5A and B). Matrix remnants were either surrounded by a clear halo ('haloed' pattern) or were attached to the vesicle limiting membrane ('semilunar' or 'marginated' pattern). In some instances, DCG appeared as empty dilated vacuole containers (Fig. 5A). Notably, altered DCG and empty containers were intermixed with normal-appearing DCG and, most significantly, these structures maintained their close morphology and were never seen to contact or fuse with the neurilemma. Besides DCG changes, small (20-30 nm in diameter) electrondense or electron-lucent vesicles were identified attached to either DCG and the plasmalemma or free in the cytoplasm. Remarkably, certain DCG exhibited outpouches of their limiting membrane, which were filled by an inner core that presented a structure and electron-density similar to that comprising the secretory material contained in DCG.

\section{Functional significance of piecemeal degranulation in neuroendocrine cells and neurons}

It is generally admitted that PMD represents a slow longlasting secretory pathway that proceeds little by little through outward vesicular transport of stored granule content. Early studies showed that PMD was expressed in basophils and mast cells infiltrating sites of chronic inflammation or cancer, and it was noted that this process differed substantially from the rapid and massive secretion occurring during compound exocytosis, which could be recognized in type I allergic reactions (anaphylactic degranulation). Subsequent analysis of PMD kinetics using ex vivo purified basophils and mast cells demonstrated that this secretory reaction allowed for particulate release of granule constituents within a time lapse of hours or even days. This pattern was therefore interpreted as being most suitable for sustaining prolonged and discrete granule release. In addition, as basophils and mast cells secrete a myriad of stored compounds, some of which exert profound biological effects at micromolar doses, it was conjectured that PMD would represent a safety mechanism preventing noxious outcomes through a careful control of releasable molecules.

This review provides evidence for a PMD pathway operating in neuroendocrine cells and neurons. The obvious question arises concerning the physiological significance of PMD in this class of cells. As previously shown, neuroendocrine cells and neurons can export transmitter cargoes from DCG through two alternative modes: 'full fusion' and 'kiss-and-run' exocytosis. Switching between these two modes would permit the cell to regulate the kinetics and amount of secretion. This process is alternatively regulated by activation of protein kinase $\mathrm{C}$ and $\mathrm{G}$ protein-coupled receptors, which modify the extent of $\mathrm{Ca}^{2+}$ influx available to initiate exocytosis $(33,79,80)$. 'Full fusion' exocytosis provides bulky extrusion of transmitter content. This implies the consequent need for a complete resynthesis of merged and collapsed granules at the trans-Golgi network. The advantages of 'full fusion' exocytosis are likely to make available a large amount of stored material on specific demand and to allow the reassembly of maximally refilled granules. 'Kiss-and-run' exocytosis, on the other hand, appears to consent export of a fraction of secretory products from individual DCG by limiting the open time of the fusion pore and to allow multiple cycles of cargo release without the necessity of entirely rebuilding the granule structure. Besides modulating the release kinetics from DCG, 'kiss-and-run' would also permit selective discharge of secretory material (Fig. 6). As a matter of fact, DCG store and release a composite pool of constituents, ranging from small and highly charged molecules, such as biogenic amines and ATP, to low molecular 


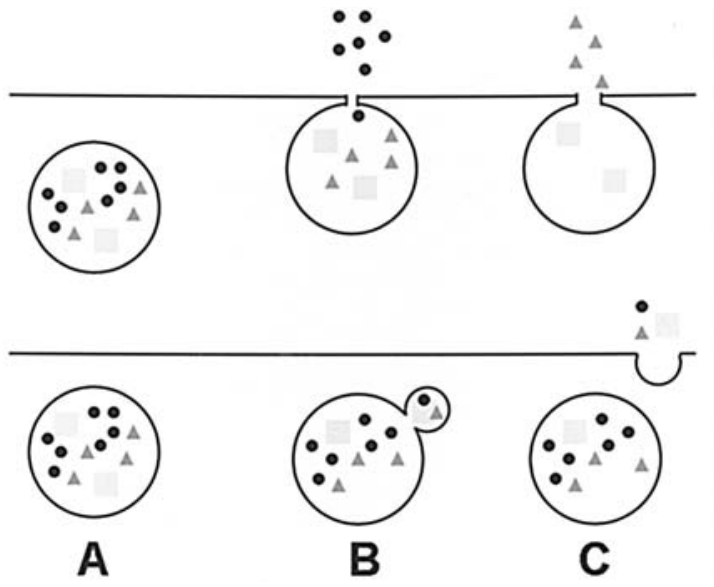

Figure 6. Comparison between 'kiss-and-run' exocytosis (top) and PMD (bottom) in dense-core granules. (A) These secretory organelles contain a composite pool of constituents, ranging from small and highly charged molecules such as biogenic amines and ATP (black circles) to low molecular weight transmitter peptides (dark grey triangles), and large matrix proteins such as chromogranins (light grey squares). (B) In 'kiss-and-run', initial pore formation determines a rapid escape of small electrically charged molecules. (C) During the phase of fusion pore expansion, larger molecules such as peptides flow out of the granule. High molecular weight structures, such as matrix proteins, are allowed to be exocyted only when the fusion pore reaches a suitable diameter or the granule collapses into the plasma membrane ('full fusion' exocytosis). By contrast, all three classes of molecules are likely to be exported through a vesicle-mediated mechanism during PMD.

weight transmitter peptides, and large matrix proteins such as chromogranins. Given the great difference in size, solubility and electrical charge of these molecules, it might be possible for fusion pores to discriminate between different releasable molecules (77). Matrix proteins, such as chromogranins, would be retained during 'kiss-and-run' exocytosis, while small molecules such as amines would rapidly escape the granule lumen once a connection to the outside via a fusion pore is established. In chromaffin cells, for instance, a fusion pore diameter $<3 \mathrm{~nm}$ may allow catecholamine release without the need of granule full fusion to the plasma membrane (81). This pore diameter, however, may prevent permeation of proteins as large as chromogranin A. If such a pore is formed transiently, it would permit complete catecholamine release without losing the proteins of the matrix. Thus, the granule may be reused and reloaded with catecholamines after closing the fusion pore. It has been demonstrated by combined capacitance measurement and real-time imaging of individual DCG that the fusion pore must dilate extensively to allow peptide release and that efflux through the early fusion pore is insignificant for peptide dismission (82). High molecular weight peptides are released as long as extensive dilation $(>4 \mathrm{~nm})$ of the fusion pore or even complete collapse of the DCG into the plasma membrane follows (82). Another factor which controls the rate of hormone release from exocyting granules is the manner in which transmitter molecules are packed within DCG. Insulin, for instance, is believed to be stored inside secretory granules as a solid hexamer bound to $\mathrm{Zn}^{2+}$ ions. During pancreatic B-cell exocytosis, it has been shown that serotonin escapes from the granule at a significantly higher rate than insulin, although both substances are released simultaneously (83). The kinetics of serotonin release during fusion pore formation is indistinguishable from simple diffusion whereas insulin exit is slower. Thus, it is likely that the insulin core, which has a diameter of 100-200 nm, must dissociate into smaller units (monomers or dimers) prior to passage through the fusion pore (84). Accordingly, it has been demonstrated that the fusion pore in pancreatic B cells appears to remain stably open (mean lifetime of $1.8 \mathrm{sec}$ ) for much longer than in other cell types such as adrenal chromaffin cells (mean lifetime of $41 \mathrm{msec}$ ) (85).

It is not clear how often recaptured DCG are used again for exocytic release. They lack the molecular machinery to refill with proteins but may reaccumulate small transmitters such as catecholamines. Tsuboi et al (84) proposed the following scenario. A first transient 'kiss-and-run' event may lead to the release of only small granule cargoes (e.g. biogenic amines, ATP and divalent metal ions). A second round of exocytosis could follow in which the granule undergoes fuller fusion, culminating in peptide release. Granules, whose peptide cargo content has been largely or completely depleted by transient fusion events, are eventually bound to lysosomal destruction because DCG biosynthesis at the trans-Golgi is the sole mechanism for rebuilding granules filled with their peptide cargo.

Considering PMD, the question arises as to why neuroendocrine cells and neurons are endowed with the faculty to express PMD, despite the fact that these cells can modify their quantal size, i.e. the amount of release per fusion event, through 'kiss-and-run' exocytosis mechanisms. In other words, what would be the advantages to neuroendocrine cells or neurons in adopting this type of secretion? In the absence of functional data on PMD in this class of cells, any conjecture is largely speculative. Our reasoning, however, can rely upon some fixed points. During PMD reaction, DCG do not release their cargoes directly to the cell exterior because granules do not fuse to the plasma membrane (Fig. 6). Thus, granule contents never make contact with the interstitial space as occurs in 'kiss-and-run' exocytosis. As a consequence, all mechanisms previously considered, leading to either diffusion or retention of DCG molecules (e.g. size and electrical charge of releasable components, and diameter and open time of the fusion pore) are inconsequential in a PMD context. This is likely to be of great functional relevance, because the process of content export out of DCG escapes in this way the deterministic sequence compelled by the 'kiss-and-run' scheme. If we apply to neuroendocrine cells and neurons what has previously emerged from studies on PMD in basophils and mast cells, we can reasonably assume that small size transmitters, such as biogenic amines and ATP, are packed with peptides and high molecular weight matrix proteins in the same transfer vesicles and dismissed altogether at the cell surface. Thus, large proteins, which are reluctant to leave DCG during a small diameter fusion pore event, may be discharged in a piecemeal fashion. This mechanism would allow a more precise modulation of the quantal size of highly toxic releasable molecules, such as adrenaline and noradrenaline, because virtually all catecholamines of a given granule are released during the transient fusion pore opening (81).

The low-level and long-lasting secretion effected by PMD seems most suitable for accomplishing paracrine secretory functions. This may possibly have a remarkable impact in 
neurobiology. PMD may support some neuron activities, such as modulatory, trophic, differentiating or inductive functions, that are believed not to be caused by fast neurotransmitter discharge but rather rely upon the protracted supply of specific molecules. An interesting open question is whether PMD may effect the selective mobilization of single transmitters out of the stored pool of releasable molecules, as suggested by studies on vesicular transport-mediated secretion in mast cells $(86,87)$. This appears to be full of potential implications for some neuroendocrine cells and neurons that stock more than one hormone/neuropeptide in their DCG.

The molecular machinery required for PMD is presently largely unspecified although some initial studies have advocated a role for SNARE proteins (88). It is likely, however, that PMD would involve recruitment and assembly of specific proteins capable of determining membrane curvature and pinching off of budding vesicles, an energetically highly unfavorable process and therefore one likely to occur very slowly (21). Shuttling vesicle formation might occur with requirement for the recruitment of epsin or other catalysts of membrane curvature and pore closure, such as dynamin II and other raft-associated proteins that drive membrane scission (11).

\section{Concluding remarks}

This review summarizes all of the evidence in support for a PMD mode of release from DCG. It is clear that the indication for PMD in neuroendocrine cells and neurons relies solely upon electron microscopic data, which provide static snapshots of granule and vesicle morphology within a given cell. A series of key issues needs to be addressed in the future. First, under what biological circumstances are DCG expected to release their cargoes in a PMD fashion? Which factors activate PMD in neuroendocrine cells and neurons, and which signals regulate the traffic of secretory vesicles to and from the plasma membrane? Second, is PMD likely to allow secretion of mixed components from DCG or is it suitable for discriminating among the wide array of stored molecules and determining the selective release of distinct bioactive constituents? Third, what is the requirement for molecular machinery during a PMD reaction involving DCG and what are the differences with the molecular recruitment in 'full fusion' or 'kiss-andrun' events? Finally, what are the physiological and pathological implications of such a releasing model? Is it suitable for accomplishing endocrine functions or rather for paracrine activities?

Given the heterogeneity of cell types containing DCG and the great assortment of secretory products stored in these organelles, which serve such different physiological specializations, it is likely that each of the above listed points may have more than one explanation. Hence, there is still much to learn about PMD in neuroendocrine cell and neuron secretion.

\section{Acknowledgments}

This work was supported by local funds from Ministero dell'Istruzione, dell'Università e della Ricerca, Rome, to the Department of Medical and Morphological Research, Anatomy Section, University of Udine.

\section{References}

1. Dvorak AM: Piecemeal degranulation of basophils and mast cells is effected by vesicular transport of stored secretory granule contents. Chem Immunol Allergy 85: 135-184, 2005.

2. Dvorak AM: Ultrastructural studies of human basophils and mast cells. J Histochem Cytochem 53: 1043-1070, 2005.

3. Erjefalt JS, Andersson M, Greiff L, Korsgren M, Gizycki M, Jeffery PK and Persson CGA: Cytolysis and piecemeal degranulation as distinct modes of activation of airway mucosal eosinophils. J Allergy Clin Immunol 102: 286-294, 1998.

4. Crivellato E, Nico B, Nussdorfer GG and Ribatti D: Catecholamine release by chromaffin cells. A lesson from mast cells. Gen Comp Endocrinol 146: 69-73, 2006.

5. Karawajczyk M, Seveus I, Garcia R, Bjornsson E, Peterson CG, Reomans GM and Venge P: Piecemeal degranulation of peripheral blood eosinophils: a study of allergic subjects during and out of the pollen season. Am J Respir Cell Mol Biol 23: 521-529, 2000.

6. Erjefalt JS, Greiff G, Andersson M, Adelroth E, Jeffrey PK and Persson CG: Degranulation patterns of eosinophil granulocytes as determinants of eosinophil driven diseases. Thorax 56: 341-344, 2001.

7. Dvorak HF and Dvorak AM: Basophilic leukocytes: structure, function and role in disease. Clin Haematol 4: 651-683, 1975.

8. Dvorak AM: Basophil and mast cell degranulation and recovery. In: Blood Cell Biochemistry. Vol. 4. Harris JR (ed). Plenum Press, New York, pp340-377, 1991.

9. Winkler $\mathrm{H}$ : The adrenal chromaffin granule: a model for large dense core vesicles of endocrine and nervous tissue. J Anat 183: 237-252, 1993.

10. Dannies PS: Protein hormone storage in secretory granules: mechanisms for concentration and sorting. Endocr Rev 20: 3-21, 1999.

11. Burgoyne RD and Morgan A: Secretory granules exocytosis. Physiol Rev 83: 581-632, 2003.

12. Wasmeier C, Bright NA and Hutton JC: The luminal domain of the integral membrane protein phogrin mediates targeting to secretory granules. Traffic 3: 654-665, 2002.

13. Wiedenmann B and Huttner WB: Synaptophysin and chromogranins/secretogranins widespread constituents of distinct types of neuroendocrine vesicles and new tools in tumor diagnosis. Virchows Arch 58: 95-121, 1989.

14. Shin OH, Rizo J and Südhof TC: Synaptotagmin function in dense core vesicle exocytosis studied in cracked PC12 cells. Nat Neurosci 5: 649-656, 2002.

15. Meldolesi J, Chieregatti E and Malosio ML: Requirements for the identification of dense-core granules. Trends Cell Biol 14: 13-19, 2002.

16. Calakos N and Scheller RH: Synaptic vesicle biogenesis, docking, and fusion: a molecular description. Physiol Rev 76: 1-29, 1996.

17. Höcker M, John M, Anagnostopoulos J, Buhr HJ, Solimena M, Gasnier B, Henry J-P, Wang TC and Wiedenmann B: Molecular dissection of regulated secretory pathways in human gastric enterochromaffin-like cells: an immunohistochemical analysis. Histochem Cell Biol 112: 205-214, 1999.

18. Kasai $\mathrm{H}$ : Comparative biology of $\mathrm{Ca}^{+2}$-dependent exocytosis: implication of kinetic diversity for secretory function. Trends Neurosci 22: 88-93, 1999.

19. Koval LM, Yavorskaya EN and Lukyanetz EA: Electron microscopic evidence for multiple types of secretory vesicles in bovine chromaffin cells. Gen Comp Endocrinol 121: 261-277, 2001.

20. Malosio ML, Giordano T, Laslop A and Meldolesi J: Densecore granules: a specific hallmark of the neuronal/neurosecretory cell phenotype. J Cell Sci 117: 743-749, 2004.

21. Jahn R, Lang T and Südhof TC: Membrane fusion. Cell 112: 519-533, 2003.

22. Artalejo CR, Elhamdani A and Palfrey HC: Dense-core vesicles can kiss-and-run too. Curr Biol 8: R62-R65, 1990.

23. Henkel AW and Almers W: Fast steps in exocytosis and endocytosis studied by capacitance measurements in endocrine cells. Curr Opin Neurobiol 6: 350-357, 1996.

24. Ryan TA: Kiss-and-run, fuse-pinch-and-linger, fuse-and-collapse: the life and times of a neurosecretory granule. Proc Natl Acad Sci USA 100: 2171-2173, 2003.

25. Taraska JW and Almers W: Bilayers merge even when exocytosis is transient. Proc Natl Acad Sci USA 101: 8780-8785, 2004.

26. Silver RB and Pappas GD: Secretion without membrane fusion: porocytosis. Anat Rec 282B: 18-37, 2005. 
27. Fesce R, Grohovaz F, Valtorta F and Meldolesi J: Neurotransmitter release: fusion or 'kiss-and-run'? Trends Cell Biol 4: 1-4, 1994.

28. Holroyd P, Lang T, Wenzel D, De Camilli P and Jahn R: Imaging direct, dynamin-dependent recapture of fusing secretory granules on plasma membrane lawns from PC12 cells. Proc Natl Acad Sci USA 99: 16806-16811, 2002.

29. Taraska JW, Perrais D, Ohara-Imaizumi M, Nagamatsu S and Almers W: Secretory granules are recaptured largely intact after stimulated exocytosis in cultured endocrine cells. Proc Natl Acad Sci USA 100: 2070-2075, 2003.

30. Steyer JA and Almers W: Tracking single secretory granules in live chromaffin cells by evanescent-field fluorescent microscopy. Biophys J 76: 2262-2271, 1999.

31. Palfrey HC and Artalejo AR: Secretion: kiss and run caught on film. Curr Biol 13: R397-R399, 2003

32. Tsuboi T and Rutter GA: Multiple forms of 'kiss-and-run' exocytosis revealed by evanescent wave microscopy. Curr Biol 13: 563-567, 2003.

33. Ales E, Tabares L, Poyato JM, Valero V, Lindau M and Alvarez de Toledo G: High calcium concentrations shift the mode of exocytosis to the kiss-and-run mechanism. Nat Cell Biol 1: 40-44, 1999.

34. Reinecke M, Hoog A, Ostenson CG, Efendic S, Grimelius L and Falkmer S: Phylogenetic aspects of pancreastatin- and chromogranin-like immunoreactive cells in the gastro-entero pancreatic neuroendocrine system of vertebrates. Gen Comp Endocrinol 83: 167-182, 1991.

35. Grube D: The endocrine cells of the digestive system: amine, peptides, and modes of action. Anat Embryol 175: 151-162, 1986.

36. Rindi G, Leiter AB, Kopin AS, Bordi C and Solcia E: The 'normal' endocrine cell of the gut: changing concepts and new evidences. Ann NY Acad Sci 1014: 1-12, 2004.

37. Nicholl CG, Polack JM and Bloom SR: The hormonal regulation of food intake, digestion and absorption. Annu Rev Nutr 5: 213-239, 1985

38. Crivellato E, Ribatti D, Mallardi F and Beltrami CA: Granule changes of human and murine endocrine cells in the gastrointestinal epithelia are characteristic of piecemeal degranulation. Anat Rec 268: 353-359, 2002.

39. Coupland RE: The Natural History of the Chromaffin Cells. Longmans, London, 1965.

40. Coupland RE and Weakley BS: Developing chromaffin tissue in the rabbit: an electron microscopic study. J Anat 102: 425-455, 1968.

41. Burgoyne RD: Control of exocytosis in adrenal chromaffin cells. Biochim Biophys Acta 1071: 174-202, 1991.

42. Langley K and Grant NJ: Molecular markers of sympathoadrenal cells. Cell Tissue Res 298: 185-206, 1999.

43. Nussdorfer GG: Paracrine control of adrenal cortical function by medullary chromaffin cells. Pharmacol Rev 48: 495-530, 1996.

44. Nussdorfer GG and Malendowicz LK: Role of tachykinins in the regulation of the hypothalamo-pituitary-adrenal axis. Peptides 19: 949-968, 1998

45. Nussdorfer GG: Proadrenomedullin-derived peptides in the paracrine control of the hypothalamo-pituitary-adrenal axis. Int Rev Cytol 206: 249-284, 2001.

46. Hochol A, Albertin G, Nussdorfer GG, Spinazzi R, Ziolkowska A, Rucinski $\mathrm{M}$ and Malendowicz LK: Effects of neuropeptides B and $\mathrm{W}$ on the secretion and growth of rat adrenocortical cells. Int J Mol Med 14: 843-847, 2004

47. Ziolkowska A, Rucinski M, Di Liddo R, Nussdorfer GG and Malendowicz LK: Expression of the beacon gene in endocrine glands of the rat. Peptides 25: 133-137, 2004.

48. Rucinski M, Andreis PG, Ziolkowska A, Nussdorfer GG and Malendowicz LK: Differential expression and function of beacon in the rat adrenal cortex and medulla. Int $\mathrm{J}$ Mol Med 16: 35-40, 2005.

49. Spinazzi R, Andreis PG and Nussdorfer GG: Neuropeptide-Y and $\mathrm{Y}$-receptors in the autocrine-paracrine regulation of adrenal gland under physiological and pathophysiological conditions (Review). Int J Mol Med 15: 3-13, 2005.

50. Conconi MT, Spinazzi R and Nussdorfer GG: The endogenous ligands of PACAP/VIP receptors in the autocrine-paracrine regulation of the adrenal gland. Int Rev Cytol 249: 1-51, 2006.

51. Steyer JA, Horstmann H and Almers W: Transport, docking and exocytosis of single secretory granules in live chromaffin cells. Nature 388: 474-478, 1997.
52. Aunis D: Exocytosis in chromaffin cells of the adrenal medulla. Int Rev Cytol 181: 213-320, 1998.

53. Crivellato E, Nico B, Perissin L and Ribatti D: Ultrastructural morphology of adrenal chromaffin cells indicative of a process of piecemeal degranulation. Anat Rec 270: 103-108, 2003.

54. Crivellato E, Belloni A, Nico B, Nussdorfer GG and Ribatti D: Chromaffin granules in the rat adrenal medulla release their secretory content in a particulate fashion. Anat Rec 277: 204-208, 2004.

55. Crivellato E, Finato N, Ribatti D and Beltrami CA: Piecemeal degranulation in human tumour pheochromocytes. J Anat 206: 47-53, 2005.

56. Crivellato E, Guidolin D, Nico B, Nussdorfer GG and Ribatti D: Fine ultrastructure of chromaffin granules in rat adrenal medulla indicative of a vesicle-mediated secretory process. Anat Embryol 211: 79-86, 2006

57. Edlund H: Pancreatic organogenesis-developmental mechanisms and implications for therapy. Nat Rev Genet 3: 524-532, 2002.

58. Erlandsen SL: Types of pancreatic islet cells and their immunocytochemical identification. Monogr Pathol 21: 140-155, 1980.

59. Reddy S and Elliott RB: Ontogenic development of peptide hormones in the mammalian fetal pancreas. Experientia 44: 1-9, 1988.

60. Kanno T, Ma X, Barg S, Eliasson L, Galvanovskis J, Göpel S, Larsson M, Renström E and Rorsman P: Large dense-core vesicle exocytosis in pancreatic B-cells monitored by capacitance measurements. Methods 33: 302-311, 2004.

61. Orci L and Malaisse W: Hypothesis: single and chain release of insulin secretory granules is related to the anionic transport at exocytotic sites. Diabetes 29: 943-944, 1980.

62. Kwan EP and Gaisano HY: Glucagon-like peptide 1 regulates sequential and compound exocytosis in pancreatic islet $\beta$-cells. Diabetes 54: 2734-2743, 2005.

63. Olsen HL, Theander S, Bokvist K, Buschard K, Wollheim CB and Gromada J: Glucose stimulates glucagon release in single rat alpha-cells by mechanisms that mirror the stimulus-secretion coupling in beta-cells. Endocrinology 146: 4861-4870, 2005.

64. Barg S: Mechanisms of exocytosis in insulin-secreting B-cells and glucagon-secreting A-cells. Pharmacol Toxicol 92: 3-13, 2003.

65. Kwok R and Evans E: Thermoelasticity of large lecithin bilayer vesicles. Biophys J 35: 637-652, 1981

66. Kendall MD: Functional anatomy of the thymic microenvironment. J Anat 177: 1-29, 1991.

67. Häkanson R, Larsson LI and Sundler F: Peptide and amine producing endocrine-like cells in the chicken thymus. Histochemistry 39: 25-34, 1974.

68. Chan AS: Ultrastructure of epithelial cells of the chick embryo thymus. Acta Anat 150: 96-103, 1994.

69. Crivellato E, Nico B and Ribatti D: Endocrine-like cells in the chick embryo thymus express ultrastructural features of piecemeal degranulation. Anat Rec 282: 106-109, 2005.

70. Thureson-Klien A: Exocytosis from large and small dense cored vesicles in noradrenergic nerve terminals. Neuroscience 10: 245-252, 1983.

71. Kelly RB: Secretory granules and synaptic vesicle formation. Curr Opin Cell Biol 3: 654-660, 1991.

72. Bean AJ, Zhang X and Hökfelt T: Peptide secretion: what do we know? FASEB J 8: 630-638, 1994.

73. Koenig JH and Ikeda K: Synaptic vesicles have two distinct recycling pathways. J Cell Biol 135: 797-808, 1996.

74. De Camilli P, Slepnev VI, Shupliakov O and Brodin L: Synaptic vesicle endocytosis. In: Synapses. Cowan WM, Südhof TC and Stevens CF (eds). Johns Hopkins Press, Baltimore, pp217-274, 2000.

75. Edwards RH: Neurotransmitter release: variations on a theme. Curr Biol 8: R883-R885, 1998.

76. Torrealba F and Carrasco MA: A review on electron microscopy and neurotransmitter systems. Brain Res Rev 47: 5-17, 2004.

77. An S and Zenisek D: Regulation of exocytosis in neurons and neuroendocrine cells. Curr Opin Neurobiol 14: 522-530, 2004.

78. Crivellato E, Nico B and Ribatti D: Ultrastructural evidence of piecemeal degranulation in large dense-core vesicles of brain neurons. Anat Embryol 210: 25-34, 2005.

79. Graham ME, Fischer RJ and Burgoyne RD: Measurement of exocytosis by amperometry in adrenal chromaffin cells: effects of clostridial neurotoxins and activation of protein kinase $\mathrm{C}$ on fusion pore kinetics. Biochimie 82: 469-479, 2000. 
80. Chen XK, Wang LC, Zhou Y, Cai Q, Prakriya M, Duan KL, Sheng ZH, Lingle C and Zhou Z: Activation of GPCRs modulates quantal size in chromaffin cells through Gß $\gamma$ and PKC. Nat Neurosci 8: 1160-1168, 2005.

81. Albillos A, Dernick G, Horstmann H, Almers W, Alvarez de Toledo $\mathrm{G}$ and Lindau M: The exocytotic event in chromaffin cells revealed by patch amperometry. Nature 389: 509-512, 1997.

82. Barg S, Olofsson CS, Schriever-Abeln J, Wendt A, GebreMedhin S, Rendtröm E and Rorsman P: Delay between fusion pore opening and peptide release from large dense-core vesicles in neuroendocrine cells. Neuron 33: 287-299, 2002.

83. Aspinwall CA, Brooks SA, Kennedy RT and Lakey JR: Effects of intravesicular $\mathrm{H}^{+}$and extracellular $\mathrm{H}^{+}$and $\mathrm{Zn}^{2+}$ on insulin secretion in pancreatic beta cells. J Biol Chem 272: 31308-31314, 1997.

84. Tsuboi T, McMahon HT and Rutter GA: Mechanisms of dense core vesicle recapture following 'kiss-and-run' ('cavicapture') exocytosis in insulin-secreting cells. J Biol Chem 279: 47115-47124, 2004
85. Takahashi N, Kishimoto T, Nemoto T, Kadowaki T and Kasai H: Fusion pore dynamics and insulin granule exocytosis in the pancreatic islet. Science 297: 1349-1352, 2002.

86. Kraeuter-Kops S, Theoharides TC, Cronin CT, Kashgarian MG and Askenase PW: Ultrastructural characteristics of rat peritoneal mast cells undergoing differential release of serotonin without histamine and without degranulation. Cell Tissue Res 262: 415-424, 1990.

87. Vliagoftis H, Dimitriadou V and Theoharides TC: Progesterone triggers selective mast cell secretion of 5-hydroxytryptamine. Int Arch Allergy Appl Immunol 93: 113-119, 1990.

88. Lacy P, Logan MR, Bablitz B and Moqbel R: Fusion protein vesicle-associated membrane protein 2 is implicated in IFNgamma-induced piecemeal degranulation in human eosinophils from atopic individuals. J Allergy Clin Immunol 107: 671-678, 2001 . 